\title{
Foreword - Selected papers of the conference Cultural HELP 2014 - Cultural heritage and loss prevention
}

Cultural heritage faces various kinds of disaster risks due to natural hazards such as floods, fires or earthquakes, as well as human induced events such as terrorism, vandalism or armed conflicts. Each year, disasters around the world show that, in addition to human losses, cultural heritage losses are also considerable. Despite this vulnerability, cultural heritage is still not given sufficient consideration in disaster risk management strategies. Few cultural heritage properties have developed disaster risk management plans and even fewer have implemented them. Among other factors, this is the result of low levels of awareness among various stakeholders and the public and of limited capacity building of those in charge of cultural heritage protection and management.

Existing international frameworks and programs for disaster risk reduction emphasize the need to develop and implement measures to reduce hazard exposure and vulnerability to disasters. Among other aspects, current disaster risk reduction initiatives recognize the importance of cultural heritage and its irreplaceable value for society, thus underlining the need to assess the impact that potential hazards may have on cultural heritage. As such, it is urgent to conduct site-based risk assessments to develop the necessary disaster risk management plans outlining mitigation, emergency preparedness, response and recovery measures for various hazards to which the properties are exposed. Additionally, to further advance heritage concerns in the wider agenda for disaster risk reduction, the needs are not only about policies, plans and management systems but also about adequate research to address the gaps in knowledge and practice.

To address these issues, the Faculty of Engineering of the University of Porto (FEUP), the Construction Institute of FEUP and the International Committee on Risk Preparedness of the International Council on Monuments and Sites organised the Cultural Heritage and Loss Prevention (Cultural HELP) conference held between the 6th and the 7th of October 2014 in Porto, Portugal. The Cultural HELP conference featured 31 presentations of international experts in cultural heritage management and protection and gathered close to 100 participants to discuss the general topic of protecting heritage from disasters and harnessing the potential of a well-maintained historic environment to strengthen the resilience of communities. Among the contributions for the Cultural HELP conference, a set of seven papers were selected for this Special Issue which elaborate on the research agenda for reducing disaster risks to cultural heritage and introduce various approaches to protect heritage from irreplaceable losses.

The paper by Ferreira, Vicente, Mendes da Silva, Varum, Costa and Maio presents a new urban fire risk assessment methodology addressing the specificities of old masonry buildings. The method is based on an existing methodology and targets large territorial scale applications. The method was applied to the old city centre of Seixal, Portugal, which involved more than 500 buildings, and the results were analysed using an integrated Geographical Information System tool. Based on the fire risk assessment results that were obtained for the old city centre of Seixal, the main fire protection and control measures that should be implemented in the near future were identified.

Still on the risk assessment topic, Romão, Paupério and Pereira propose a simplified risk assessment framework specifically developed for the multi-hazard risk analysis of built immovable cultural heritage assets. The framework can be used as a screening procedure for the preliminary assessment of a large number of assets with limited resources and can also be used to identify cultural heritage assets that require a more refined and resource demanding risk evaluation. The methodology is based on a set of structured assessment flowcharts that address the main components of a risk analysis: the likelihood of the hazard, the vulnerability of the asset to the hazard, the consequences of the hazard, the loss of value of the asset and the capacity to recover from the event. The applicability of the methodology is illustrated with an application example for the case of seismic risk.

In terms of the risk mitigation topic, the paper by Marion analyses why hazards develop into disasters. The research investigates a detailed, risk-informed, approach to better address these hazards, in particular fire, and more effectively and efficiently protect cultural heritage. The paper highlights several important factors that need to be accounted for when developing mitigation strategies for cultural heritage constructions, such as reflecting the sensitive historic nature of the building, identifying and incorporating indigenous traditions, minimizing the intrusiveness/visibility of the mitigation measures and minimizing the impact on historic fabric.

To illustrate how the impacts of rising damp in historical heritage walls can be mitigated, Guimarães, Delgado and de Freitas present the performance of a wall base ventilation technology based on "in situ" results of the rising damp treatment conducted in a Portuguese historical church. The results, registered over four years, show the best ventilations periods and also show the difference in terms of absorption behaviour between walls with and without joints. The paper also analyses the results of an experimental campaign dealing with water absorption in samples of clay brick with and without joints, and with joints exhibiting different contact configurations (perfect contact, hydraulic continuity and air space between layers). 
Still on the topic of mitigation, Okubo revisits the importance of traditional knowledge and construction techniques for disaster mitigation. The paper discusses design strategies of Japanese traditional buildings and cities that enabled them to survive disasters throughout history. Specific examples addressing different hazards such as earthquake, fire, flood, tsunami and windstorm are presented, highlighting the materials and technologies that were used to achieve the desired performance. The integration of this traditional knowledge and disaster mitigation techniques with modern technologies is also discussed.

In terms of interventions for risk mitigation and conservation, Ornelas, Guedes and Breda-Vázquez present a comparative study of different building standards addressing interventions on the built heritage. The study focuses on three Southern European countries with comparable cultural approaches (Italy, Spain and Portugal) and identifies categories and heritage values, inventory and cataloguing processes, as well as intervention levels. This systematic analysis highlights the importance of these issues for the need to establish flexible and minimum criteria of intervention to achieve the maximum preservation of the built heritage. The paper presents an overview of the standards and legislation of the referred countries and discusses criteria and measures to support an integrated approach in built heritage interventions.

Finally, Alshweiky and Unal discuss the specific aspects related to the conservation and preservation of the Al-Haram Al-Ibrahimi sacred site located in Hebron, Palestine. The research addresses the historical background of the building complex until it was divided into two sites in 1997 as a result of tensions between Israel and Palestine. This condition creates several issues for the holistic conservation of the site which start by the inability of surveying the building as a whole. The presented research aims to discuss possible solutions for the conservation and risk management of Al-Haram Al-Ibrahimi, as well as to evaluate the role of international organizations related with cultural heritage conservation in this specific case.

Xavier Romão* CONSTRUCT-LESE, Faculty of Engineering, University of Porto, Porto, Portugal

Esmeralda Paupério Construction Institute, CONSTRUCT-LESE, Faculty of Engineering, University of Porto, Porto, Portugal

Rohit Jigyasu

International Scientific Committee on Risk Preparedness of the International Council on Monuments and Sites (ICORP-ICOMOS), Ritsumeikan University, Kyoto, Japan

*Corresponding author. Tel.: +351 22508 1956; fax: +35122508 1835 . E-mail address: xnr@fe.up.pt (X. Romão)

Received 10 June 2016

Accepted 10 June 2016

Available online 13 July 2016 